African Journal of Microbiology Research Vol. 6(6), pp. 1197-1205, 16 February, 2012

Available online at http://www.academicjournals.org/AJMR

DOI: 10.5897/AJMR11.1414

ISSN 1996-0808 @2012 Academic Journals

\title{
Assessment of culturable airborne fungi in a university campus in Hangzhou, southeast China
}

\author{
Xiuqin Lou', Zhiguo Fang ${ }^{2 \star}$ and Chanjuan Gong ${ }^{2}$ \\ ${ }^{1}$ Hangzhou Center for Disease Control and Prevention, Hangzhou, 310021, China. \\ ${ }^{2}$ College of Environmental Science and Engineering, Zhejiang Gongshang University, Hangzhou 310012, China.
}

Accepted 27 December, 2011

\begin{abstract}
Airborne fungi, which may adversely affect human health through allergy, infection, and toxicity, are being proposed as a cause of adverse health effects. In this study, a systematic survey on culturable airborne fungi was conducted for one year in four areas of the university campus in Hangzhou, southeast of China: living area (LA), dining area (DA), teaching area (TA), and office area (OA). Results showed that the mean concentration of culturable fungal was about $1104 \mathrm{CFU} / \mathrm{m}^{3}$. Pencillium was the most common fungal group, and contributed to more than $36 \%$ of the total fungal concentration, followed by Cladosporium, Alternaria, and Asperigillus isolates. Fungal concentration in DA was highest $\left(1271 \mathrm{CFU} / \mathrm{m}^{3}\right)$, while the concentration in OA was lowest $\left(791 \mathrm{CFU} / \mathrm{m}^{3}\right)$. The seasonal variation pattern of fungal concentration in a year was significant in LA, DA and TA, where the concentrations were higher in spring and summer, and lower in autumn and winter $\left({ }^{\star \star} P<0.01\right)$. However, there were no significant differences in fungal concentration in OA. With regarding to the size distribution of airborne fungi, there were no significance among different areas and seasons, all appeared as normal logarithm distribution. Moreover, airborne fungi was mostly collected in stage 3 (3.0 to $6.0 \mu \mathrm{m})$, stage 4 (2.0 to 3.5 $\mu \mathrm{m}$ ) and stage $5(1.0$ to $2.0 \mu \mathrm{m})$, and totally composing $83.55 \%$ of the population in LA, $83.96 \%$ in DA, $85.14 \%$ in TA, and $79.39 \%$ in OA. It suggested that a more efficient monitoring network and forewarning system of airborne microorganisms in the public areas should be gradually constructed in China.
\end{abstract}

Key words: University campus, airborne fungi, Penicillium, concentration distribution, size distribution.

\section{INTRODUCTION}

In 1998, the Chinese government proposed expand university enrollment of professional and specialized graduates and developed world class universities, and the enrollment in higher education increased drastically from 1.6 to 3.82 million between 1999 and 2003. China had 6.3 million students to graduate from college or university in 2010 (Liu et al., 2000). Meanwhile, the

${ }^{\star}$ Corresponding author. E-mail: zhgfang77@yahoo.com.cn; zhgfang77@zjgsu.edu.cn. Tel: +86-571-88071024-7011. Fax: +86-571-88905799.

Abbreviations: LA, Living area; DA, dining area; TA, teaching area; $\mathbf{O A}$, office area; CFU, colony forming units. infrastructure construction at the university or college could not keep up with the expanding program very well, and the campus of many universities became relatively crowded. As a special public place, attentions should be focused on developing and applying disease control and prevention policies in these universities. However, problems of public health in universities were not concerned enough in China. Centers for Disease Control and Prevention (CDCs) have developed a systematic monitoring network of public health only in primary and middle schools. In fact, activities of disease prevention and control (infectious diseases, food-borne pathogens and other microbial infections), health promotion, environmental health should be also designed to improve the health of students in universities. Environmental 
problems, especially the air quality in the crowed places in universities, should be significantly concerned of, since outbreaks of many epidemic diseases are correlated with microorganisms in the air (for example, influenza $A$ pandemic (H1N1) 2009 were frequently reported in universities in 2009).

Fungi are ubiquitous in the atmosphere, and often constitute the main biological component of the air. They are considered to be closely related with air pollution and human health. Exposure to bio-aerosols containing airborne microorganisms and their by-products can result in respiratory disorders and other adverse health effects such as infections, hypersensitivity pneumonitis and toxic reactions (Harrison et al., 1992; Hargreaves et al., 2003; Fracchia et al., 2006). As a whole, more than 80 genera of fungi were associated with symptoms of respiratory tract allergies (Horner at al., 1995), and over 100 species of fungi were involved with serious human and animal infections, while many other species caused serious plant diseases (Cvetnic and Pepelnjak, 1997). It was reported that Cladosporium, Alternaria, Penicillium, Aspergillus in the atmosphere were the most common fungi (Shelton et al., 2002; Adhikari et al., 2004), and their concentrations differed from place to place because of local environmental variables, fungal substrates, and human activities (Shelton et al., 2002). The potential of health risk caused by exposure to airborne fungi could occur in workplaces and residential spaces at any time. The concern about adverse health effects from bioaerosol inhalation has led to consideration of permissible exposure limits for fungi. However, currently there are seldom specific standards or directives or other exposure limits for fungi.

As an important indicator, airborne fungi investigation in university campus was considered to be necessary for their impacts on the human health. Many studies were carried out about the fungal community in outdoor, indoor and even underground environments (Bogomolova and Kirtsideli, 2009). However, little is known about the characteristics of airborne fungi in southeast of China, including in the campus of universities. Hangzhou is one of the most suitable to live cities in China, and generally speaking, its environment is pretty well. We chose a university in Hangzhou to survey on both concentration distribution and community of airborne fungi, to evaluate whether it is indispensable to construct monitoring network and forewarning system systematically and extensively in those areas.

\section{MATERIALS AND METHODS}

\section{Sampling sites}

Hangzhou is the capital and largest city of Zhejiang Province in southeast of China with a registered population of 8.7 million. It has a humid subtropical climate with four distinctive seasons, characterized by long, very hot, humid summers and short, chilly, cloudy and dry winters (with occasional snow). The average annual temperature is $16.5^{\circ} \mathrm{C}\left(61.7^{\circ} \mathrm{F}\right)$, ranging from $4.3^{\circ} \mathrm{C}\left(39.7^{\circ} \mathrm{F}\right)$ in January to $28.4^{\circ} \mathrm{C}\left(83.1^{\circ} \mathrm{F}\right)$ in July. The city receives an average annual rainfall of $1,450 \mathrm{~mm}$ (57.1 in) and is affected by the plum rains of the Asian monsoon in June. (Hangzhou Climate and Weather; http://www.topchinatravel.com/hangzhou/hangzhouclimate-and-weather.html). In the present study, four sampling sites located in the campus of Zhejiang Gongshang University in Hangzhou city were selected for the study of culturable airborne fungi: (1) LA, a dormitory with the area of about $20 \mathrm{~m}^{2}$ on the second floor of a building in Zhejiang Gongshang University. There are 6 graduate students living in it, and the indoor environment is not so clean. They do the sweeping about once a week. (2) DA, a canteen about $400 \mathrm{~m}^{2}$ on the first floor of Xinlanyuan Building in Zhejiang Gongshang University. It can hold more than 300 people for dinner, and there are special barrels for plate and bowl leftover near the door. The indoor environment is pretty well, and they do the sweeping after each dinner. (3) TA, an extremely large classroom that can hold more than 130 students. The indoor environment is ordinary, not so clean or dirty. (4) OA, a teacher office about $15 \mathrm{~m}^{2}$ on the second floor in a building. There are 3 teachers working in it, and with 3 office tables and 2 bookcases. The indoor environment is very well, and the teachers sweep the floor and open the window every day.

\section{Sampling methods}

A six-stage culture-able FA-1 sampler (imitated Andersen sampler), made by the Applied Technical Institute of Liaoyang, China, and was used to isolate culturable fungi from the atmosphere. Each stage includes a plate with 400 holes of uniform diameter through which air is drawn at $28.3 \mathrm{I} \mathrm{min}^{-1}$ to impact on Petri dishes containing agar media. Airborne particles are separated into six fractions, and the aerodynamic cut-size diameters in six stages are $7.0 \mu \mathrm{m}$ (stage 1), 4.7 to $7.0 \mu \mathrm{m}$ (stage 2), 3.3 to $4.7 \mu \mathrm{m}$ (stage 3), 2.1 to $3.3 \mu \mathrm{m}$ (stage 4), 1.1 to $2.1 \mu \mathrm{m}$ (stage 5), and 0.65 to $1.1 \mu \mathrm{m}$ (stage 6), respectively. In each sampling site, the sampler was mounted on $1.5 \mathrm{~m}$ above ground level with a platform. Sampling was conducted seasonally, in Oct. 2009 (autumn), Jan 2010 (winter), Apr 2010 (spring), and Jul 2010 (summer), respectively in a year. All of the samples were collected at 2:00 pm for 3 min in triplex, and continued for three consecutive days of each season. For each sampling, the FA-1 sampler was loaded with $9.0 \mathrm{~cm}$ Petri dishes containing sabouraud agar adding chloramphenicol to inhibit bacterial growth. Exposed culture dishes were incubated for $72 \mathrm{~h}$ at $25^{\circ} \mathrm{C}$. Results were then expressed as colony forming units per cubic meter of air $\left(\mathrm{CFU} / \mathrm{m}^{3}\right)$.

\section{Sample analysis}

\section{Fungal concentration qualification}

Colony forming units (CFU) on each plate were counted and concentration of samples was expressed as CFU per cubic meter of air $\left(\mathrm{CFU} / \mathrm{m}^{3}\right)$. However, since the superposition is unavoidable when the microbial particles impact the same spot through the same sieve pore, the colonies collected was revised by $1 . \mathrm{CFU} / \mathrm{m}^{3}$ was calculated by 2 .

$$
P_{r}=N\left(\frac{1}{N}+\frac{1}{N-1}+\frac{1}{N-2}+\cdots+\frac{1}{N-r+1}\right)
$$


$C\left(C F U / m^{3}\right)=\frac{\left(P_{1}+P_{2}+P_{3}+P_{4}+P_{5}+P_{6}\right) \times 1000}{t(\min ) \times F(L / \mathrm{min})}$

In the equations, $P_{r}$ is the revised colony in every stage ( $r$ is from 1 to 6); $\mathrm{N}$ is the number of sieve pore in every stage of the sampler; $r$ is the sampling colony; $C$ is airborne fungal concentration; $P_{1}, P_{2}$, $P_{3}, P_{4}, P_{5}$, and $P_{6}$ is the revised colony in every stage in the sampler; $t$ is the sampling time; $F$ is the air flow rate of sampler during sampling (Fang et al., 2007).

\section{Fungal particle percentage qualification at every stage in the} sampler

The fungal particle percentage at every stage was calculated by 3 .

$F P_{\mathrm{r}}=\frac{P_{\mathrm{r}}}{P_{1}+P_{2}+P_{3}+P_{4}+P_{5}+P_{6}}$

In the equation, $\mathrm{FP}_{\mathrm{r}}$ is the fungal particle percentage ( $\mathrm{r}$ is from 1 to 6); $P_{r}$ is the revised colony in every stage ( $r$ is from 1 to 6 ); $P_{1}, P_{2}$, $P_{3}, P_{4}, P_{5}$, and $P_{6}$ is the revised colony in every stage in the sampler.

\section{Fungal identification}

After incubation, fungal colonies growing on each dish were counted and identified microscopically to their genus groups according to the morphology of the observed hyphae, conidia, and sporangia. Fungal colonies sub-cultured onto malt extract agar (MEA), or other appropriate media that have not developed sporing structures after 14 days were described as "non-sporing isolates". Fungal isolates selected from sampling sites were in further identified using the molecular method as described below. Each pure isolate was homogenized in liquid culture medium and then DNA was extracted using CATB method (Möller et al., 1992). The internal transcribed spacer (ITS) region of fungal rRNA genes was amplified using the following universal primer set: ITS ${ }_{1}\left(5^{\prime}\right.$ TCCGTAGGTGAACCTGCGG-3') and ITS ${ }_{4}$ (5'TCCTCCGCTTATTGATATGC-3')(White et al., 1990). The reaction mixture $(50 \mu \mathrm{l})$ consisted of $0.3 \mu \mathrm{l}$ Taq polymerase, $2 \mu \mathrm{l}$ dNTP, 5 $\mu \mathrm{L} 10 \times \mathrm{PCR}$ buffer, $2 \mu \mathrm{l}$ each primer, and $1.0 \mu \mathrm{l}$ (ca. $10 \mathrm{ng}$ DNA) template. The amplification program was as follows: initial denaturation at $94^{\circ} \mathrm{C}$ for $5 \mathrm{~min}, 30$ cycles of $94^{\circ} \mathrm{C}$ for $30 \mathrm{~s}$, annealing at $55^{\circ} \mathrm{C}$ for $30 \mathrm{~s}$, and extension at $72^{\circ} \mathrm{C}$ for $30 \mathrm{~s}$, and then final extension for $10 \mathrm{~min}$ at $72^{\circ} \mathrm{C}$. The PCR products were detected by electrophoresis on a $1 \%$ agarose gel. The sequences were obtained using prime T7 by the Shanghai Majorbio Bio-technology Company, and were analyzed with the BLAST program of the National Center for Biotechnology Information (NCBI) (http://www.ncbi.nlm.nih.gov/Blast.cgi). The sequences showing the highest similarity to those of the clones were extracted from GenBank.

\section{Statistical analysis}

All the experimental data were analyzed using SPSS Version 17.0 and Microsoft Excel 2007. The multiple comparative analysis method of ANOVA and Duncan's test was used to assess the differences of concentrations of airborne fungi among the investigated sites. The significant differences of airborne fungal concentrations were analyzed by means of paired t-test.

\section{RESULTS}

\section{Community composition of culturable airborne fungi in the university campus}

Totally, eighteen genera of culturable airborne fungi were identified from the sampling sites in the university campus (Table 1). The frequency of the five groups including Pencillium, Cladosporium, Alternaria, Asperigillus, and non-sporing isolates varied from 66.7 to $100.0 \%$ in LA, DA, TA, and OA throughout a sampling year, while the frequency of other fungal groups varied from 0.0 to $50.0 \%$.

Within all the identified groups of culturable airborne fungi, Pencillium had the maximum fungal concentration percentage in all the sampling sites, followed by Cladosporium, Alternaria, Asperigillus and Non-sporing isolates (Table 1). Their concentration percentages varied from 4.3 to $13.9 \%$. Other groups accounted for no more than $10.0 \%$ of total fungi colonies in the university campus. Therefore, the dominant culturable airborne fungi identified from the university campus were Pencillium, Cladosporium, Alternaria, Asperigillus and non-sporing isolates due to their frequency and concentration percentage.

\section{Concentration distribution of culturable airborne fungi in the university campus}

\section{Spatial variation pattern of culturable airborne fungal concentration}

The concentration and its range of culturable airborne fungi in four sampling sites in the university campus were showed in Table 2. Considering all sampling area, the mean and geometric mean concentration of culturable airborne fungi were $1104 \mathrm{CFU} / \mathrm{m}^{3}$, and $1028 \mathrm{CFU} / \mathrm{m}^{3}$ respectively in the university campus. Significant highest fungal concentrations were found in DA, followed by LA and TA, while lowest fungal concentration was detected in $O A\left({ }^{* *} P<0.01\right)$. The mean fungal concentration was about $1202 \mathrm{CFU} / \mathrm{m}^{3}$ in LA, $1271 \mathrm{CFU} / \mathrm{m}^{3}$ in $\mathrm{DA}, 1151$ $\mathrm{CFU} / \mathrm{m}^{3}$ in $\mathrm{TA}$, and $791 \mathrm{CFU} / \mathrm{m}^{3}$ in OA. The concentrations of Penicillius and Cladosporium in LA, DA, and DA were higher than those in $O A \quad\left({ }^{* *} P<0.01\right)$, and no significant difference was found among LA, TA, and DA $(P>0.05)$. Significant higher concentrations of Alternaria were determined in LA and DA than in TA and OA. Concerning Aspergillus group, highest concentration was observed in $D A$, while lowest in $O A\left({ }^{* *} P<0.01\right)$.

\section{Seasonal variation pattern of culturable airborne fungal concentration}

Significant differences in total fungal concentrations among seasons existed in LA, TA and DA, where 
Table 1. Concentration percentage and frequency of airborne fungi in four sampling sites at the university.

\begin{tabular}{|c|c|c|c|c|c|c|c|c|}
\hline \multirow[b]{2}{*}{ Fungal types } & \multicolumn{2}{|c|}{ LA } & \multicolumn{2}{|c|}{ DA } & \multicolumn{2}{|c|}{ TA } & \multicolumn{2}{|c|}{ OA } \\
\hline & $\begin{array}{c}\text { Frequency } \\
\text { (\%) }\end{array}$ & $\begin{array}{l}\text { Concentration } \\
\text { percentage (\%) }\end{array}$ & $\begin{array}{c}\text { Frequency } \\
(\%)\end{array}$ & $\begin{array}{l}\text { Concentration } \\
\text { percentage (\%) }\end{array}$ & $\begin{array}{c}\text { Frequency } \\
\text { (\%) }\end{array}$ & $\begin{array}{l}\text { Concentration } \\
\text { percentage (\%) }\end{array}$ & $\begin{array}{c}\text { Frequency } \\
\text { (\%) }\end{array}$ & $\begin{array}{c}\text { Concentration } \\
\text { percentage (\%) }\end{array}$ \\
\hline Alternaria & 83.3 & 13.6 & 83.3 & 12.6 & 75.0 & 11.4 & 91.7 & 13.9 \\
\hline Aspergillus & 83.3 & 6.7 & 75.0 & 7.4 & 66.7 & 6.3 & 66.7 & 8.0 \\
\hline Cladosporium & 91.7 & 27.9 & 83.3 & 27.0 & 100.0 & 28.4 & 91.7 & 25.2 \\
\hline Penicillium & 100 & 40.0 & 100.0 & 41.1 & 100.0 & 40.1 & 100.0 & 36.1 \\
\hline No-sporing & 100 & 4.3 & 100.0 & 4.6 & 100.0 & 5.6 & 100.0 & 6.6 \\
\hline Paecilomyces & 16.7 & 0.3 & 8.3 & 0.2 & 25.0 & 0.6 & 8.3 & 0.2 \\
\hline Monilia & 33.3 & 0.7 & 25.0 & 1.0 & 16.7 & 0.5 & 41.7 & 1.2 \\
\hline Fusarium & 16.7 & 0.2 & 33.3 & 0.9 & 41.7 & 1.7 & 16.7 & 0.5 \\
\hline Phoma & 41.7 & 0.7 & 50.0 & 1.4 & 33.3 & 0.8 & 33.3 & 1.7 \\
\hline Saccharomyce & 25.0 & 0.6 & 16.7 & 0.5 & 16.7 & 0.5 & 16.7 & 0.5 \\
\hline Mucor & 16.7 & 0.3 & 8.3 & 0.2 & 16.7 & 0.3 & 8.3 & 0.4 \\
\hline Rhizopus & 16.7 & 0.2 & 8.3 & 0.2 & 8.3 & 0.2 & 8.3 & 0.4 \\
\hline Trichoderma & 8.3 & 0.1 & 0.0 & 0.0 & 8.3 & 0.2 & 0.0 & 0.0 \\
\hline Talaromyces & 8.3 & 0.2 & 16.7 & 0.3 & 0.0 & 0.0 & 25.0 & 0.9 \\
\hline Eurotium & 8.3 & 0.2 & 0.0 & 0.0 & 0.0 & 0.0 & 0.0 & 0.0 \\
\hline Trametes & 0.0 & 0.0 & 8.3 & 0.1 & 0.0 & 0.0 & 0.0 & 0.0 \\
\hline Chaetomium & 0.0 & 0.0 & 8.3 & 0.2 & 8.3 & 0.3 & 8.3 & 0.2 \\
\hline Neurospora & 8.3 & 0.3 & 0.0 & 0.0 & 25.0 & 0.8 & 25.0 & 1.0 \\
\hline No-identification & 91.7 & 3.7 & 91.7 & 2.3 & 100.0 & 2.4 & 100.0 & 3.1 \\
\hline
\end{tabular}

the mean concentrations were higher in spring (months from Mar to May) and summer (months from Jun to Aug), and lower in autumn (months from Sep to Nov) and winter (months from Dec to Feb) $\left({ }^{* *} \mathrm{P}<0.01\right)$, while no significant variation of fungal concentrations was observed in different seasons in $\mathrm{OA} \quad(\mathrm{P}>0.05)$ (Figure 1). Higher Penicillius and Cladosporium concentration was found in spring and summer, then lower in autumn and winter in LA, DA, TA and OA. As for Alternaria and Aspergillus, significant seasonal variation pattern of their concentration was observed in LA, DA and TA, higher in spring and summer, lower in autumn and winter $\left({ }^{*} \mathrm{P}<0.05\right)$. In $\mathrm{OA}$, the concentration of Alternaria and Aspergillus presented no significant difference in a year $(P>0.05)$.

\section{Particle size distributions of culturable airborne fungi in the university campus}

\section{Spatial variation pattern of particle size distribution}

Particle size distribution of culturable airborne fungi in four sampling sites in the university campus was demonstrated in Figure 2. Basically, same particle size distribution pattern was observed in LA, DA, DA and OA in the university campus, and no significant difference ofthe size distribution pattern was found among these functional areas $(P>0.05)$. The proportion of culturable airborne fungi increased gradually from stage1 $(>8.2 \mu \mathrm{m})$ to stage4 $(2.0$ to $3.5 \mu \mathrm{m})$, and decreased dramatically at stage $5(1.0$ to $2.0 \mu \mathrm{m})$ and stage $6(<1.0 \mu \mathrm{m})$. The distributing patterns of culturable airborne fungi presented log-normal distribution. Most culturable airborne fungi 
Table 2. Concentration characteristics and its range of airborne fungi in four sampling sites at the university.

\begin{tabular}{|c|c|c|c|c|c|c|c|c|}
\hline \multirow[b]{2}{*}{ Fungal types } & \multicolumn{2}{|c|}{ LA } & \multicolumn{2}{|c|}{ DA } & \multicolumn{2}{|c|}{ TA } & \multicolumn{2}{|c|}{ OA } \\
\hline & $\begin{array}{c}\text { Concentration } \\
\left(\mathrm{CFU} / \mathrm{m}^{3}\right)\end{array}$ & $\begin{array}{c}\text { Concentration } \\
\text { range }\end{array}$ & $\begin{array}{l}\text { Concentration } \\
\left(\mathrm{CFU} / \mathrm{m}^{3}\right)\end{array}$ & $\begin{array}{c}\text { Concentration } \\
\text { range }\end{array}$ & $\begin{array}{c}\text { Concentration } \\
\left(\mathrm{CFU} / \mathrm{m}^{3}\right)\end{array}$ & $\begin{array}{c}\text { Concentration } \\
\text { range }\end{array}$ & $\begin{array}{c}\text { Concentration } \\
\left(\mathrm{CFU} / \mathrm{m}^{3}\right)\end{array}$ & $\begin{array}{c}\text { Concentration } \\
\text { range }\end{array}$ \\
\hline Alternaria & 162.9 & $0-285.0$ & 160.1 & $0-346.8$ & 131.2 & $0-237.2$ & 110.2 & $0-177.3$ \\
\hline Aspergillus & 80.7 & $0-141.8$ & 94.6 & $0-177.6$ & 72.8 & $0-141.9$ & 62.9 & $0-106.2$ \\
\hline Cladosporium & 335.8 & $0-623.0$ & 343.1 & $0-614.4$ & 326.5 & $177.6-625.4$ & 199.4 & $0-272.8$ \\
\hline Penicillium & 480.4 & 200.8-771.5 & 522.5 & $153.7-1080.2$ & 461.6 & 260.8-708.6 & 285.8 & 189.2-368.1 \\
\hline No-sporing & 44.3 & $11.8-94.7$ & 59.1 & 11.8-142.2 & 27.5 & 11.8-47.2 & 24.6 & $0-47.3$ \\
\hline Paecilomyces & 3.9 & $0-35.5$ & 3.0 & $0-35.5$ & 64.0 & $11.8-94.7$ & 52.2 & $35.5-70.9$ \\
\hline Monilia & 8.8 & $0-35.5$ & 12.8 & $0-83.0$ & 6.9 & $0-35.5$ & 2.0 & $0-23.6$ \\
\hline Fusarium & 2.9 & $0-23.6$ & 11.8 & $0-47.3$ & 5.9 & $0-47.3$ & 9.8 & $0-35.5$ \\
\hline Phoma & 8.8 & $0-23.6$ & 17.7 & $0-47.3$ & 19.7 & $0-59.0$ & 3.9 & $0-35.5$ \\
\hline Saccharomyce & 6.9 & $0-35.5$ & 5.9 & $0-47.3$ & 8.8 & $0-35.5$ & 13.8 & $0-35.5$ \\
\hline Mucor & 3.9 & $0-23.6$ & 2.0 & $0-23.6$ & 5.9 & $0-35.5$ & 3.9 & $0-23.6$ \\
\hline Rhizopus & 2.9 & $0-23.6$ & 2.0 & $0-23.6$ & 3.9 & $0-35.5$ & 3.0 & $0-35.5$ \\
\hline Trichoderma & 1.0 & $0-11.8$ & 0.0 & $0-0$ & 2.0 & $0-35.5$ & 3.0 & $0-35.5$ \\
\hline Talaromyces & 2.0 & $0-23.6$ & 3.9 & $0-23.6$ & 2.0 & $0-35.5$ & 0.0 & $0-0$ \\
\hline Eurotium & 2.0 & $0-23.6$ & 0.0 & $0-0$ & 0.0 & $0-0$ & 6.9 & $0-35.5$ \\
\hline Trametes & 0.0 & $0-0$ & 1.0 & $0-11.8$ & 0.0 & $0-0$ & 0.0 & $0-0$ \\
\hline Chaetomium & 0.0 & $0-0$ & 2.0 & $0-23.6$ & 0.0 & $0-0$ & 0.0 & $0-0$ \\
\hline Neurospora & 3.9 & $0-11.8$ & 0.0 & $0-0$ & 3.0 & $0-35.5$ & 2.0 & $0-23.6$ \\
\hline No-identification & 51.1 & $0-70.9$ & 29.5 & $0-58.9$ & 8.9 & $0-47.3$ & 7.9 & $0-35.5$ \\
\hline Total fungi & 1202.4 & - & 1270.9 & - & 1150.5 & - & 791.0 & - \\
\hline
\end{tabular}

were distributed at stage 3 , stage 4 and stage 5 in the sampler, totally contributing with $83.55,83.96$, 85.14 and $79.39 \%$ in the LA, DA, TA and OA, respectively. Just a few airborne fungi were found at stage 1 , stage 2 (5.0 to $10.4 \mu \mathrm{m})$ and stage 6 in the sampler. The highest proportions of culturable airborne fungi were detected at stage 4 and the lowest at stage 6 . The proportions were $43.56 \%$ (LA), $43.51 \%$ (DA), $46.36 \%$ (TA) and $42.76 \%$ (OA) at stage 4 , and $2.28 \%$ (LA), $1.03 \%$ (DA),
$1.24 \%(\mathrm{TA})$ and $1.98 \%(\mathrm{OA})$ at stage 6.

\section{Seasonal variation pattern of particle size distribution}

Just as particle size distribution of culturable airborne fungi in four sampling sites, the distributing patterns of culturable airborne fung presented log-normal distribution (Figure 3), and no significant difference of the size distribution pattern was found among seasons in the year $(P>0.05)$. Most culturable airborne fungi were distributed at stage 3 (3.0 to $6.0 \mu \mathrm{m})$, stage 4 and stage 5 in the sampler, totally contrubuting to $86.13,86.57,81.88$ and $77.45 \%$ in spring, summer, autumn and winter respectively. The highest proportions of culturable airborne fungi were detected at stage 4 and the lowest, at stage 6. The proportions were $46.69 \%$ (LA), $45.80 \%$ 

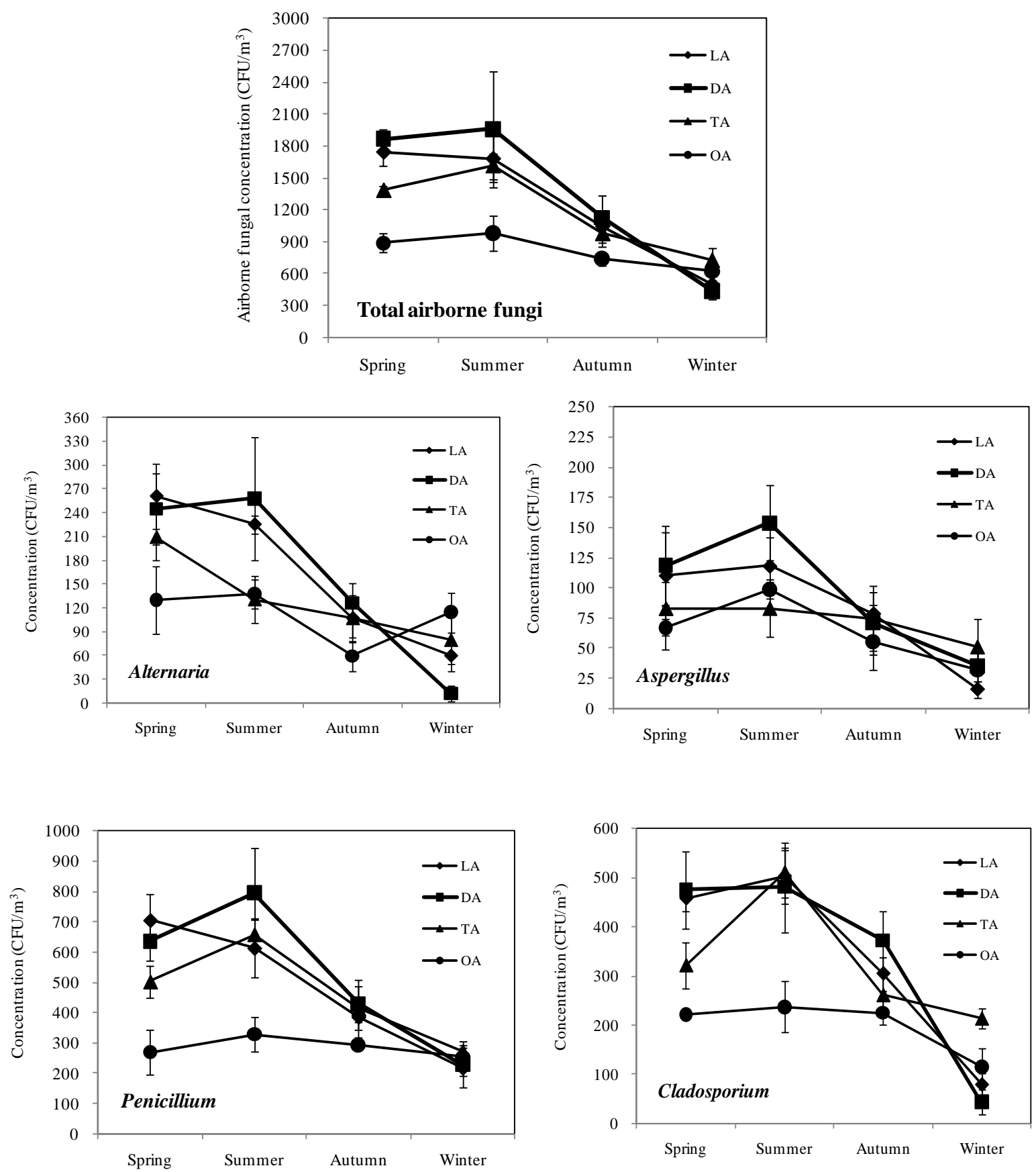

Figure 1. Seasonal variation pattern of airborne fungal concentration in four sampling sites at the university.

(DA), $42.44 \%$ (TA) and $41.24 \%(\mathrm{OA})$ at stage 4 , and $1.02 \%$ (LA), $0.92 \%$ (DA), $1.25 \%$ (TA) and $3.34 \%(\mathrm{OA})$ at stage 6.

\section{DISCUSSION}

It is an urgent need to undertake the study of indoor airborne fungi to generate baseline data and explore their link to nosocomial infections, to establish lawfully regulated standards related to airborne microorganisms. The U.S. Environmental Protection Agency (EPA) conducted the Building Assessment Survey and Evaluation (BASE) over a five-year period from 1994 to 1998, to characterize determinants of indoor air quality including aerosol dispersal of pathogens such as airborne bacteria 


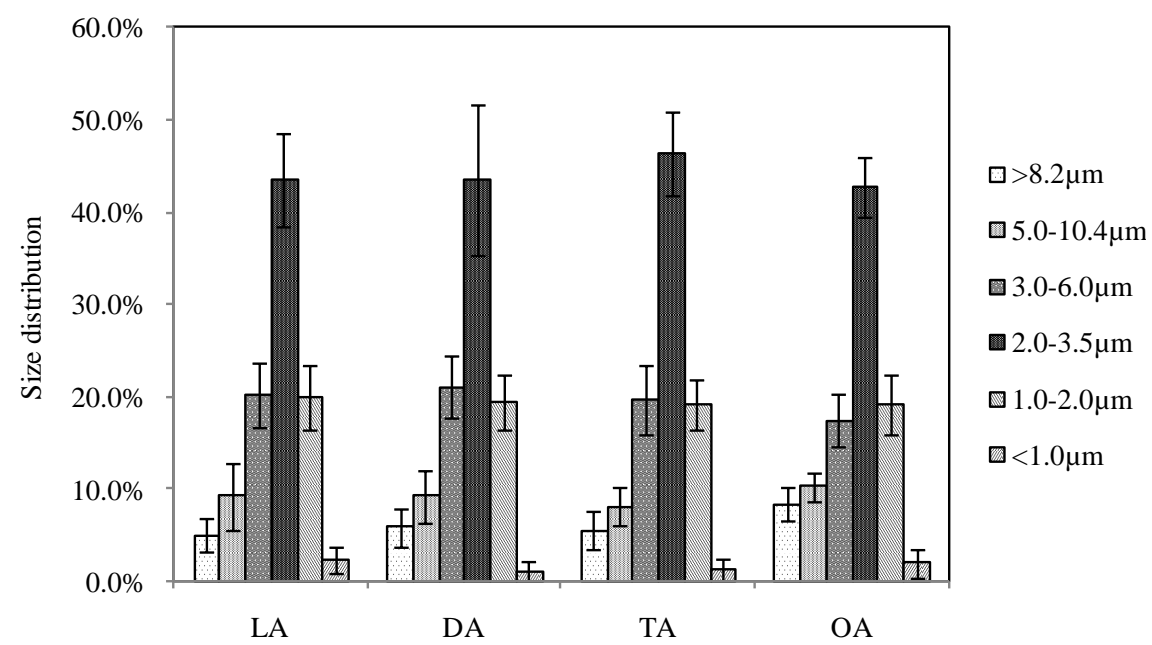

Figure 2. Size distribution of airborne fungi in four sampling sites at the university.

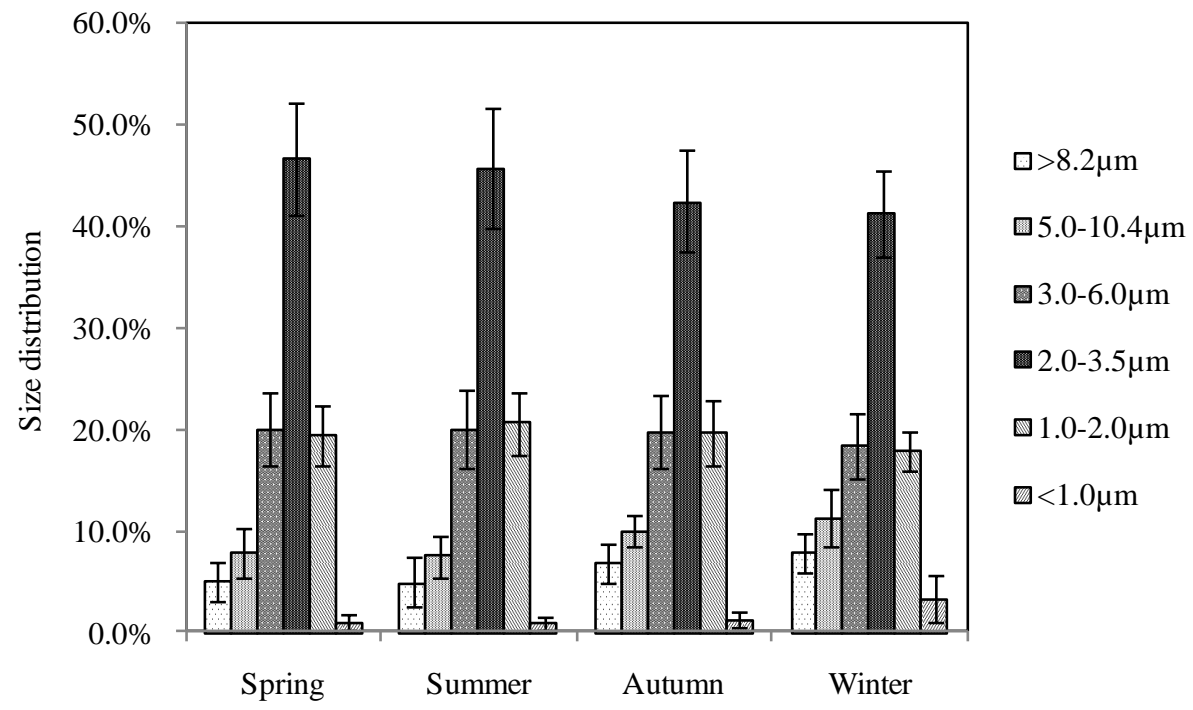

Figure 3. Size distribution of airborne fungi in different seasons in a year at the university.

and fungi (Sarica et al., 2002). In 2001, the German Federal Environmental Office also initiated a research project, the UFOPLAN (Umweltforschungsplans) study, to determine the background concentrations of indoor mold in order to standardize mold measurement procedures in non-moldy homes (Baudisch et al., 2009). However, to date in China, the network of sanitaryepidemiological responsible for microbiological measurements/control in indoor air is not sufficient at all. CDCs in China only monitor the total concentration of airborne bacteria and fungi in the public indoor places such as stations and hotels according to Chinese National Standard (GB/T 18204.1-2000). Further studies should be carried out to get enough baseline data and develop a more comprehensive monitoring network of airborne microorganisms in China. Airborne fungi of the indoor and outdoor environments has attracted much public attention especially in south China, since its humid climatic characteristics are appropriate for mold growth and reproduction. Our results provided the first hand data of airborne fungi baseline in southeast of China, and could efficiently help to evaluate the human health risks from exposure to these atmosphere.

The community composition, concentration variation, and size distribution of airborne culturable fungi in LA, $D A, T A$, and OA in the university campus, southeast of 
China, was performed seasonally in a sampling year. In general, the fungal concentration in the indoor environment of university campus in Hangzhou city was higher compared to the studies conducted in other areas (Lee et al., 2006; Kim and Kim, 2007), which suggested that we should carefully focused on the public health problems associated with elevated concentration of airborne fungi because long time exposure to these indoor environments may lead to high risk of human health. The main cause of higher fungi concentration in Hangzhou might be attributed to its climatic characteristics, since it has a humid subtropical climate with four distinctive seasons (very long, hot, humid summers and short, chilly, cloudy, dry winters). What's more, Hangzhou city has relatively high vegetation coverage, and the vigorous growth of plants might provide much fungal growth substrates in the air (Ju et al., 2003; Fang et al., 2005).

It was shown that fungal concentration in DA was highest $\left(1271 \mathrm{CFU} / \mathrm{m}^{3}\right)$, followed by LA (1202 $\mathrm{CFU} / \mathrm{m}^{3}$ ) and TA $\left(1151 \mathrm{CFU} / \mathrm{m}^{3}\right)$, while the concentration in OA was lowest $\left(791 \mathrm{CFU} / \mathrm{m}^{3}\right)$. Two sampling sites of LA and OA were with almost the same square area (20 vs. 15 $\mathrm{m}^{2}$ ) and both on the 2nd floor of the building, however, compared to OA, LA with six male graduate students seems more crowed, with more personal activities and worse ventilation, and the room was not so clean because there are mess of cloths, socks, and other daily supplies, suggesting that human activities, cleanness, and ventilation were the major factors that influenced the concentration of indoor airborne fungi. The same reasons were also for the larger space of DA and TA, for DA with many people and much leftover at the front of the door at the mealtime, and TA with many students for their classes frequently. Meanwhile, leftover in the dining area, especially in the hot and wet seasons, might be the favourable growth substrates for airborne fungi. Therefore, it was reasonable that DA was with highest concentration of airborne fungi. As to its seasonal variation pattern, fungi concentrations were higher in spring and summer, and lower in autumn and winter $\left({ }^{\star *} \mathrm{P}<0.01\right)$ in $L A, D A$ and $T A$, whereas there were no significant differences in fungi concentrations in $\mathrm{OA}$ where the air-conditioner could keep the temperature relatively more stable with the change of seasons, indicating that air temperature was another important factor for airborne fungi.

The most common fungi groups in LA, DA, TA, and OA in the university campus were Pencillium, Cladosporium, Alternaria, and Asperigillus according to priority, and Pencillium contributed to more than $36 \%$ of the total fungal concentration. High concentration of Pencillium and Cladosporium in indoor environment could cause allergic diseases(Li 1997), and Cladosporium were also associated with respiratory symptoms (Su et al., 1992). Asperigillus were the most infections, commonest airborne fungi; it could cause a group of diseases called aspergillosis which could occur in immune- compromised hosts or as a secondary infection. Symptoms of aspergillosis include persistent cold, watering eyes, prolonged muscle cramps and joint pain (Vonberg and Gastmeier, 2006). It has been reported that Pencillium was the most prevalent airborne fungi in indoor environments such as public buildings in Korea (Kim and Kim, 2007). However, many studies indicated that the most common fungi in indoor air was Cladosporium (Lee et al., 2006), and our former findings carried out in outdoor environments in Beijing was also Cladosporium (Fang et al., 2005). This might be caused by the great differences of environmental conditions (such as climate characteristics, vegetation coverage, human activities, etc).

The size distribution of fungi-associated aerosol particles was also conducted in this study. Our results showed that the distributions were similar in different sampling sites, presenting log-normal distribution, which was in accordance with the studies of Meklin et al. (2003) in school buildings of two construction types (wooden and concrete) and our previous study in outdoor environment in Beijing city (Fang et al., 2005). In our study, the highest fungal levels were located in the 2.0 to $3.5 \mu \mathrm{m}$ size range, and lowest in $<1 \mu \mathrm{m}$. It was shown that the deposition of fungal spores in lung and their effects on human health not only depended on their composition (genera and species) and concentration, but also their size. Larger spores $(>10 \mu \mathrm{m})$ were deposited in the upper airway (nose, pharynx) and might result in hay fever symptoms, while smaller spore particles (diameter $<10 \mu \mathrm{m}$, especially $<5 \mu \mathrm{m}$ ) could penetrate the lower airways and might lead to other allergies or asthma (Horner et al., 1995). Attached or unattached fungal allergens that were in the ultra fine range $(<0.1 \mu \mathrm{m})$ or sub-micrometre size, respectively, could penetrate to the deepest parts of the respiratory tract (Horner et al., 1995).

With regard to the fungal identification methods, obvious disadvantages have been emerged for direct fungal identification by microscopy because it is a tedious and time consuming process (Williams et al., 2001), and it also must be identified by considering their morphology. The method of PCR by using the specific primer sets can identify the specific fungi efficiently (Yap et al., 2009), but the fungal species in air environments were relatively abundant and hard to make a full-scale prediction. What's more, conventional PCR analysis has certain limitations, particularly in its accuracy, reliability and reproducibility (Birch et al., 2001). Here, we used culture methods, followed by sequencing and BLAST the ITS gene to determine the fungi species. This molecular method of fungal typing seems to have a good performance, for this reason, it could help to finish the identification work efficiently, with a high-throughput process referred to a standard operating procedure and reliable results. 


\section{Conclusion}

We found that the airborne fungal concentration was relatively high in these crowed places in the university campus in China. The findings of this paper suggest that Chinese government and research institutes should pay more attention to the biological pollution in the crowed public places such as the university campus, and then gradually construct a more efficient monitoring network of airborne microorganisms in the public areas in China.

\section{ACKNOWLEDGEMENTS}

This study was financially supported by the Project of National Natural Science Foundation of China (No. 41005085), and the Project of Natural Science Foundation of Zhejiang Province (No. Y5100365), and the Open Fund Project of Research Center for EcoEnvironmental Sciences, Chinese Academy of Sciences, and the Starting Research and Fund Project of Ministry of Education of returned overseas students. Authors also thank the teachers who provided their valuable suggestions and the graduate students who performed the microbial investigation in the campus air at Zhejiang Gongshang Univeristy, Hanghzhou, Zhejiang Province.

\section{REFERENCES}

Adhikari A, Sen M, Gupta-Bhattacharya S, Chanda S (2004). Volumetric assessment of airborne fungi in two sections of a rural indoor dairy cattle shed. Environ. Int.; 29: 1071-8.

Baudisch C, Assadian O, Kramer A (2009). Concentration of the genera Aspergillus, Eurotium and Penicillium in 63-microm house dust fraction as a method to predict hidden moisture damage in homes. BMC Publ. Health, 9: 247.

Birch L, Archard C, Parkes H, McDowell D (2001). Evaluation of LabChip technology for GMO analysis in food. Food Control, 12: 53540.

Bogomolova E, Kirtsideli I (2009). Airborne fungi in four stations of the St. Petersburg Underground railway system. Int. Biodeterioration Biodegradation 63: 156-60.

Cvetnic Z, Pepelnjak S (1997). Distribution and mycotoxin-producing ability of some fungal isolates from the air. Atmos. Environ., 31: 4915 .

Fang Z, Ouyang Z, Hu L, Wang X, Zheng H, Lin X (2005). Culturable airborne fungi in outdoor environments in Beijing, China. Sci. Total Environ., 350: 47-58.

Fang Z, Ouyang Z, Zheng H, Wang X, Hu L (2007). Culturable Airborne Bacteria in Outdoor Environments in Beijing, China. Microbial Ecol., 54: 487-96.

Fracchia L, Pietronave S, Rinaldi M, Martinotti M (2006). The assessment of airborne bacterial contamination in three composting plants revealed site-related biological hazard and seasonal variations. J. Appl. Microbiol., 100: 973-84.
Hangzhou Climate \& Weather http://www.topchinatravel.com/hangzhou/hangzhou-climate-andweather.htm.

Hargreaves M, Parappukkaran S, Morawska L, Hitchins J, He C, Gilbert D (2003). A pilot investigation into associations between indoor airborne fungal and non-biological particle concentrations in residential houses in Brisbane, Australia. Sci. Total Environ., 312: 89101.

Harrison J, Pickering C, Faragher E, Austwick P, Little S, Lawton L (1992). An investigation of the relationship between microbial and particulate indoor air pollution and the sick building syndrome. Respir. Med., 86: 225-35.

Horner W, Helbling A, Salvaggio J, Lehrer S (1995). Fungal allergens. Clin. Microbiol. Rev., 8: 161-79.

Ju T, Suo A, Tian Y, Feng K (2003). Analysis on aerobiologia in Lanzhou (in Chinese). Ind. Saf. Environ. Prot., 29: 17-9.

Kim K, Kim C (2007). Airborne microbiological characteristics in public buildings of Korea. Building Environ., 42: 2188-96.

Lee T, Grinshpun S, Martuzevicius D, Adhikari A, Crawford C,Reponen $T$ (2006). Culturability and concentration of indoor and outdoor airborne fungi in six single-family homes. Atmos. Environ., 40: 2902 10.

Li C, Hsu L (1997). Airborne fungus allergen in association with residential characteristics in atopic and control children in a subtropical region. Arch. Environ. Health 52: 72-9.

Liu L, Krahmer M, Fox A, Feigley C, Featherstone A, Saraf A, Larsson L (2000). Investigation of the concentration of bacteria and their cell envelope components in indoor air in two elementary schools. J. Air Waste Manag. Assoc., 50: 1957-67.

Meklin T, Hyvarinen A, Toivola M, Reponen T, Koponen V, Husman T, Taskinen T, Korppi M, Nevalainen A (2003). Effect of building frame and moisture damage on microbiological indoor air quality in school buildings. AlHA J (Fairfax, Va); 64: 108-16.

Möller E, Bahnweg G, Sandermann H, Geiger H (1992). A simple and efficient protocol for isolation of high molecular weight DNA from filamentous fungi, fruit bodies, and infected plant tissues. Nucleic Acids Res., 20: 6115-6.

Sarica S, Asan A, Otkun M, Ture M (2002). Monitoring indoor airborne fungi and bacteria in the different areas of Trakya University Hospital, Edirne, Turkey. Indoor Built. Environ., 11: 285-92.

Shelton B, Kirkland K, Flanders W, Morris G (2002). Profiles of Airborne Fungi in Buildings and Outdoor Environments in the United States Appl. Environ. Microbiol., 68: 1743-53.

Su H, Rotnitzky A, Burge H, Spengler J (1992). Examination of fungi in domestic interiors by using factor analysis: correlations and associations with home factors. Appl. Environ. Microbiol., 58: 181-6.

Vonberg R, Gastmeier P (2006). Nosocomial aspergillosis in outbreak settings. J. Hosp. Infect., 63: 246-54.

White T, Bruns T, Lee S, Taylor J (1990). Amplification and direct sequencing of fungal ribosomal RNA genes for phylogenetics. In PCR Protocols: Guide Methods Appl., 2:76-80.

Williams R, Ward E, McCartney H (2001). Methods for integrated air sampling and dna analysis for detection of airborne fungal spores. Appl. Environ. Microbiol., 67: 2453-59.

Yap J, Toh Z, Goh V, Ng L, Vesper S (2009). Assessment of mold concentrations in Singapore shopping centers using mold-specific quantitative PCR (MSQPCR) analysis Indian J. Microbiol., 49: 290-3. 